\title{
Extreme Gravity Waves In The Arabian Gulf
}

\author{
S. Neelamani*, K. Al-Salem, and K. Rakha \\ * Coastal and Air Pollution Department, Environment and Urban Development Division, Kuwait Institute for Scientific Research, \\ P.O. Box . 24885, 13109 Safat, Kuwait
}

Received 29 May 2007; accepted 8 September 2007

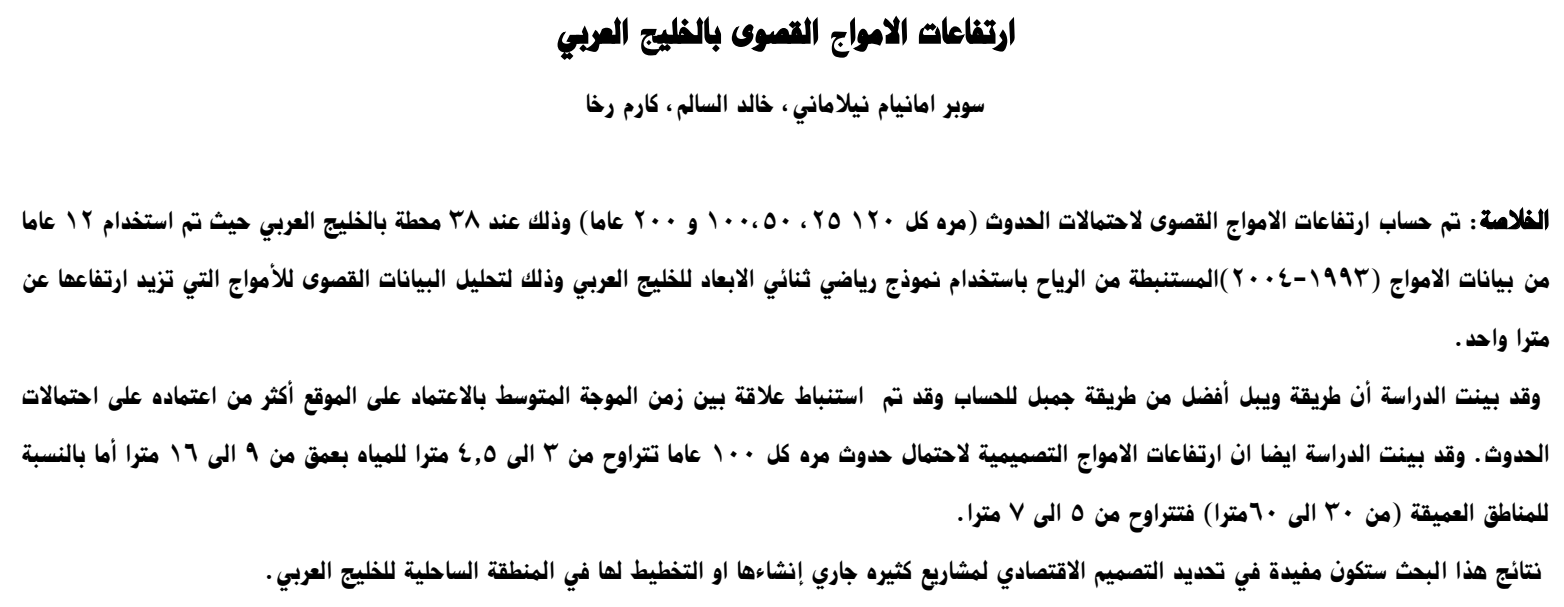

الهزرهات الهثاهية: ارتفاعات الأهواج القصوى ، الخليج العربي ،طريقة جهبل و ويبل للتحليل ، ارتفاعات الامواج، زهن الموجة، بيانات الامواج المستنبطة من الرياح.

\begin{abstract}
The extreme significant wave heights and the corresponding mean wave periods were predicted for return periods of 12, 25, 50, 100 and 200 years for 38 different locations in the territorial and offshore locations of countries surrounding the Arabian Gulf. The input wave data for the study is hindcast waves obtained using a WAM model for a total period of 12 years, (1993 to 2004). The peak over threshold method (with $1.0 \mathrm{~m}$ as threshold value), is used for selecting the data for the extreme wave analysis. In general, a Weibull distribution is found to fit the data well compared to the Gumbel distribution for all these locations. From the joint probability of wave height and wave period, a simple polynomial relationship ( $\left.T_{\text {mean }}=C_{3}\left(H_{s}\right)^{C 4}\right)$ is used to obtain the relationship between the significant wave height and mean wave period for all the 38 locations. The value of $C_{3}$ is found to vary from 3.8 to 4.8 and the value of $C_{4}$ is found to vary from 0.19 to 0.32 . The mean wave period was found to be more sensitive to change in locations within the Gulf and it is less sensitive to change in return periods from 12 years to 200 years. The significant wave heights for 100 year return period varied from 3.0 to 4.5 for water depths of 9 to $16 \mathrm{~m}$, whereas in the offshore sites (depths from 30 to $60 \mathrm{~m}$ ) it varied from 5.0 to 7.0 $m$. A large number of coastal projects are in progress in the Arabian Gulf and many new projects are being planned in this region for the future. The results of the present study will be highly useful for optimal design of the ocean structures for these projects.
\end{abstract}

Keywords: Extreme waves, Arabian Gulf, Gumbel and Weibull distribution, Significant wave height, Mean wave period, Hindcasted wave data

\section{Introduction}

Establishing the design environmental conditions (like design wave height, wind speed, current speed) for different types of marine structures (seawater intake structures, breakwaters, port and harbor structures, shore protection structures, submarine pipelines, open sea loading/unloading terminals, oil terminals and offshore platforms etc.) is

*Corresponding author’s E-mail:nsubram@kisr.edu.kw very essential from safety and economic point of view. A lack of correct information on environmental design condition will result either in an unsafe structure or an over designed (and hence uneconomical) structure. Therefore it is very essential to predict the design wave heights for different return periods correctly. As on date, in the Arabian Gulf, most of the coastal structures appear to be over designed, since no systematic extreme wave height prediction is available. Recently Neelamani, et al. (2006) has carried out the extreme wave analysis, especially for 
Kuwaiti territorial waters for a total of 19 locations. This study provides an extension of previous study to cover the whole Arabian Gulf for the benefit of the GCC countries for the safe and cost effective design of coastal and offshore structures.

The wave conditions in the Arabian Gulf are relatively low, since it is basically fetch limited. The Arabian Gulf, a marginal sea in a typical arid zone, is an arm of the Indian Ocean. It lies between the latitude of 24-30 degree $N$. The gulf covers an area of 226,000 square $\mathrm{km}$. It is $990 \mathrm{~km}$ long and its width ranges from 56 to $338 \mathrm{~km}$. It has a total volume of 7000 to $8400 \mathrm{~km}^{3}$ of seawater (Emery, K.O., 2006; Purser, B.H., Seibold, E., 1973; ElGindy, A., Hegazi, M., 1996; and Al-Yamani, F.Y., et al. 2004). The entire basin lies upon the continental shelf. The average water depth of the Arabian Gulf is about 35.0 $m$. But depths more than $107 \mathrm{~m}$ occur in some places. The gulf's water depth increases in the south east direction. The Gulf is connected to the Gulf of Oman and the Arabian Sea through the Strait of Hormuz, which is $56 \mathrm{~km}$ wide and with an average water depth of $107 \mathrm{~m}$ and allows water exchange between the Arabian Gulf and Arabian Sea. In the Arabian Gulf, in general the dominant wind direction is northwesterly (Elshorbagy, et al. 2006). Arabian Gulf is one of the very active marine areas on the earth. Most of the oil produced in the Gulf countries is transported through the Arabian Gulf waters. It is also strategically important area. Most of the countries around the Arabian Gulf rely on the seawater for desalination and for cooling purposes in power plants. A large number of coastal and offshore project activities are going on/being planned in the Arabian Gulf waters like artificial coastal developmental projects such as palm and world shaped water fronts in Dubai, Durrat Al-Bahrain - a jewelry shaped water front development in Bahrain and similar projects in Qatar, ultra modern ports in Kuwait, a number of submarine pipeline and offshore oil and gas platforms, projects for development of tourism industries etc. Design of all these varieties of marine structures require estimate of design wave height for different return periods, which is not available at present. An attempt is made in the present paper to report the extreme waves in the Arabian Gulf waters for different return periods. Caires and Sterl, (2005) have estimated the 100 year return value for significant wave height from the ERA-40 data for the whole oceans of the earth. The wind data used in this study is obtained from grid of $1.5^{\circ} \times 1.5^{\circ}$. Unfortunately this course grid can not provide much information for the countries surrounding the Arabian Gulf, since the width of the Arabian Gulf itself is of the order of $1.5^{\circ}$ only. In this study wind data on a finer grid size of $0.5^{\circ} \times 0.5^{\circ}$ was used and the wind speeds are linearly interpolated to the WAM model grid size of $0.1^{\circ} \times 0.1^{\circ}$.

\section{Literature Review}

Large number of works were done by many scientists around the world on extreme value prediction of winds and waves. Gumbel (1958) is the first who has developed a statistical method for predicting the extreme values of natural random events like wind speed. Recorded annual maximum wind speed for as many years as possible, is the input for this method. Gumbel's extreme value distribution is widely used by the wind engineering community around the world, since the method is simple and robust. St. Denis (1969 and 1973) has discussed Gumbel distribution in the context of extreme wave prediction. Information related to the collection of data samples for extreme value analysis can be found from Nolte (1973), Cardone, et al. (1976), Petrauskas and Aagaard (1971) and Jahns and Wheeler (1973). Details regarding the plotting formula used for the extreme wave predictions are available in Kimball (1960), Gringorten (1963) and Petrauskas and Aagaard (1971). The procedure to extreme wave height predictions are explained in Sarpkaya and Isaacson (1981) and in Kamphuis (2000). Extreme value analysis for waves is discussed in detail in Mathiesen, et al. (1994) Goda, et al. (1993) and Goda (1992). Coles (2001) has provided the statistical details of extreme value prediction based on the annual maximum data points and Peak Over Threshold (POT) method. Additional information on POT and its application is provided in Ferreira and Guedes Soares (1998) and Leadbetter (1991). All these literatures provide the information and knowledge for carrying out detailed extreme value analysis and are used for the present work.

\section{Input Data Generation}

In this study, the wave data is hindcasted using a WAM model for a total period of 12 years, starting from $1^{\text {st }}$ Jan 1993 to $31^{\text {st }}$ December 2004. The WAM model is a thirdgeneration wind driven wave model. The WAM model is a two dimensional model that uses non-stationary and non-homogeneous wind fields in predicting wind waves. The physical processes included in the model are: windwave interaction (generation), wave-wave interaction (quadruplet), dissipation (white capping) and shallowwater bottom dissipation (bottom friction). The output from the WAM model is the significant wave height and the mean wave period for every one hour. The data is hindcasted for the whole Arabian Gulf waters with a grid size of $0.1^{\circ} \times 0.1^{\circ}$. The model was validated using measured data as provided in (Al-Salem, et al. 2005). The measurements covered a period of about four years where the wave height and period were recoded at a wave Buoy and two towers. The model results showed some under prediction in the wave heights for storm events. This was due to the under prediction in the wind speed for such events. Using regression analysis, a suitable correction was proposed for waves exceeding $1.0 \mathrm{~m}$ Rakha, et al. 2007).

Figure 1 provides a sample of the corrected model results for the significant wave height $H_{s}$ and the mean 

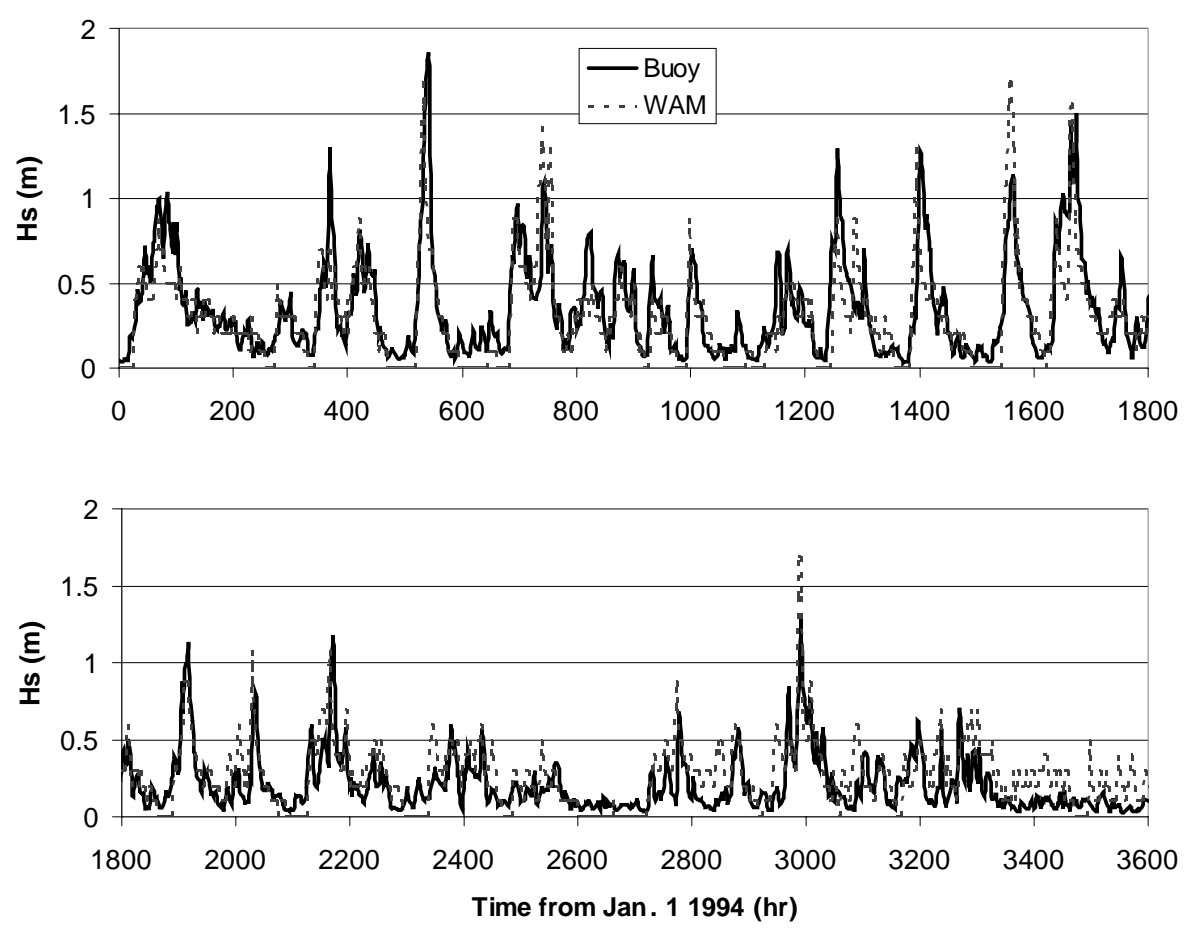

Figure 1. Comparison between measured and predicted wave conditions (year 1994, at wave buoy form)

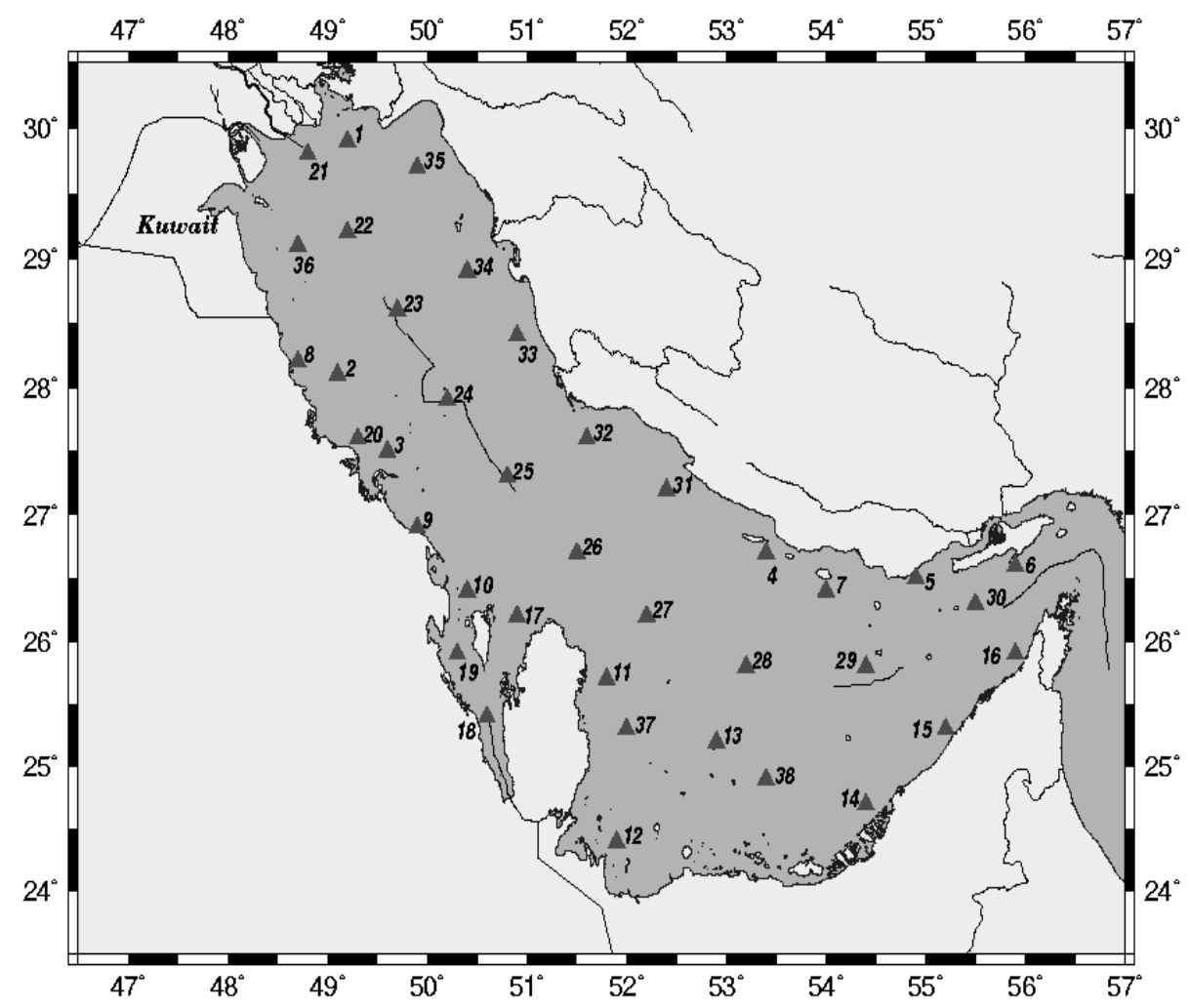

GMT May 23 10:35:42 2006

Figure 2. Locations in the Arabian Gulf waters for extreme wave analysis

wave period $T_{m}$ at the wave Buoy. It can be seen that the model predicts $H_{s}$ and $T_{m}$ very well. More results on the model validation can be found in Al-Salem, et al. (2005) and Rakha, et al. (2007).
The extreme wave analysis is carried out for a total of 38 different locations in the Arabian Gulf as shown in Fig. 2. Each location has a total of 105, 192 hourly wave conditions. The longitude, latitude and the water depth of each location is given in Table 1. 
Table 1. Longitude, Latitude and local water depth at 38 different locations in the Arabian Gulf waters

\begin{tabular}{|c|c|c|c|c|}
\hline Location & $\begin{array}{c}\text { Longitude } \\
\left({ }^{\circ} \mathrm{E}\right)\end{array}$ & $\begin{array}{c}\text { Latitude } \\
\left({ }^{0} \mathbf{N}\right)\end{array}$ & $\begin{array}{l}\text { Water depth } \\
\text { (m) }\end{array}$ & Remarks/Nearest Country \\
\hline 1 & 49.2 & 29.9 & 15 & Iran \\
\hline 2 & 49.1 & 28.1 & 15 & Saudi Arabia \\
\hline 3 & 49.6 & 27.5 & 15 & Saudi Arabia \\
\hline 4 & 53.4 & 26.7 & 61 & Iran \\
\hline 5 & 54.9 & 26.5 & 11 & Iran \\
\hline 6 & 55.9 & 26.6 & 31 & Iran \\
\hline 7 & 54.0 & 26.4 & 55 & Iran \\
\hline 8 & 48.7 & 28.2 & 9 & Saudi Arabia \\
\hline 9 & 49.9 & 26.9 & 16 & Saudi Arabia \\
\hline 10 & 50.8 & 26.4 & 12 & Bahrain \\
\hline 11 & 51.8 & 25.7 & 19 & Qatar \\
\hline 12 & 51.9 & 24.4 & 10 & UAE \\
\hline 13 & 52.9 & 25.2 & 16 & UAE \\
\hline 14 & 54.4 & 24.7 & 10 & UAE \\
\hline 15 & 55.2 & 25.3 & 16 & UAE \\
\hline 16 & 55.9 & 25.9 & 20 & UAE \\
\hline 17 & 50.9 & 26.2 & 9 & North west of Qatar \\
\hline 18 & 50.6 & 25.4 & 17 & South west of Qatar \\
\hline 19 & 50.3 & 25.9 & 20 & $\begin{array}{l}\text { In between Saudi Arabia and } \\
\text { Bahrain }\end{array}$ \\
\hline 20 & 49.3 & 27.6 & 9 & Saudi Arabia \\
\hline 21 & 48.8 & 29.8 & 10 & In between Kuwait -Iran \\
\hline 22 & 49.2 & 29.2 & 33 & In between Saudi Arabia -Iran \\
\hline 23 & 49.7 & 28.6 & 45 & In between Saudi Arabia -Iran \\
\hline 24 & 50.2 & 27.9 & 48 & In between Saudi Arabia -Iran \\
\hline 25 & 50.8 & 27.3 & 62 & In between Bahrain -Iran \\
\hline 26 & 51.5 & 26.7 & 39 & In between Qatar -Iran \\
\hline 27 & 52.2 & 26.2 & 44 & In between Qatar -Iran \\
\hline 28 & 53.2 & 25.8 & 54 & In between UAE -Iran \\
\hline 29 & 54.4 & 25.8 & 59 & In between UAE -Iran \\
\hline 30 & 55.5 & 26.3 & 57 & In between UAE -Iran \\
\hline 31 & 52.4 & 27.2 & 79 & Iran \\
\hline 32 & 51.6 & 27.6 & 22 & Iran \\
\hline 33 & 50.9 & 28.4 & 42 & Iran \\
\hline 34 & 50.4 & 28.9 & 44 & Iran \\
\hline 35 & 49.9 & 29.7 & 24 & Iran \\
\hline 36 & 48.7 & 29.1 & 19 & Kuwait \\
\hline 37 & 52.0 & 25.3 & 15 & East of Qatar \\
\hline 38 & 53.4 & 24.9 & 20 & UAE \\
\hline
\end{tabular}

The maximum and average significant wave heights for these 38 locations based on the 12 year hindcasted data is provided in Fig. 3. The highest maximum significant wave height is hindcasted at location $28\left(H_{s}=5.33 \mathrm{~m}\right)$ and the lowest maximum significant wave height is hindcasted at location $8\left(H_{s}=1.82 \mathrm{~m}\right)$. Similarly the maximum average wave height for 12 year has occurred at location 27 with $H_{s}=0.77 \mathrm{~m}$ and the minimum average wave height has occurred at location 5 with $H_{s}=0.21 \mathrm{~m}$.

\section{Methodology}

The Gumbel and Weibull distribution is used for the extreme value prediction. The input data point selection is

done carefully. The statistics of long term prediction of wave requires that the individual data points used in the statistical analysis be statistically independent. Hence any hourly wave height depends very much on the wave height of the previous hours and hence the theoretical condition of statistical independence is not met. Hence, in order to produce independent data points, only storms should be considered. The commonly used method to separate wave heights into storms is called Peak Over Threshold (POT) analysis (Coles 2001). Mathiesen, et al. (1994) recommends that the minimum time interval between local maxima be somewhat longer than the time lag for which the auto-correlation function is 0.3 to 0.5 . They also recommend that generally a time interval of two to four days suffices. For the present work with 12 years 


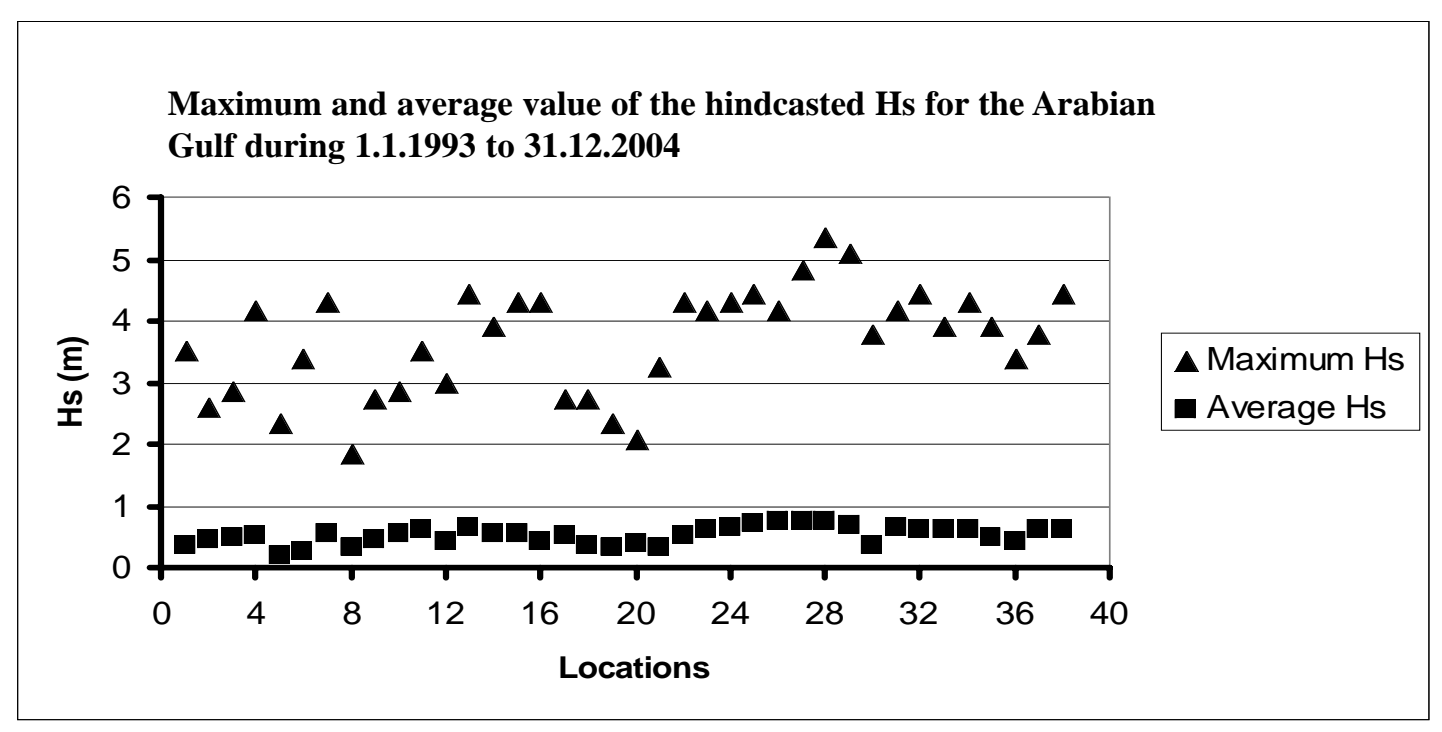

Figure 3. Maximum and average value of the hindcasted significant wave height for Arabian Gulf waters based on the hindcasted waves from 1.1.1993 to 31.12.2004

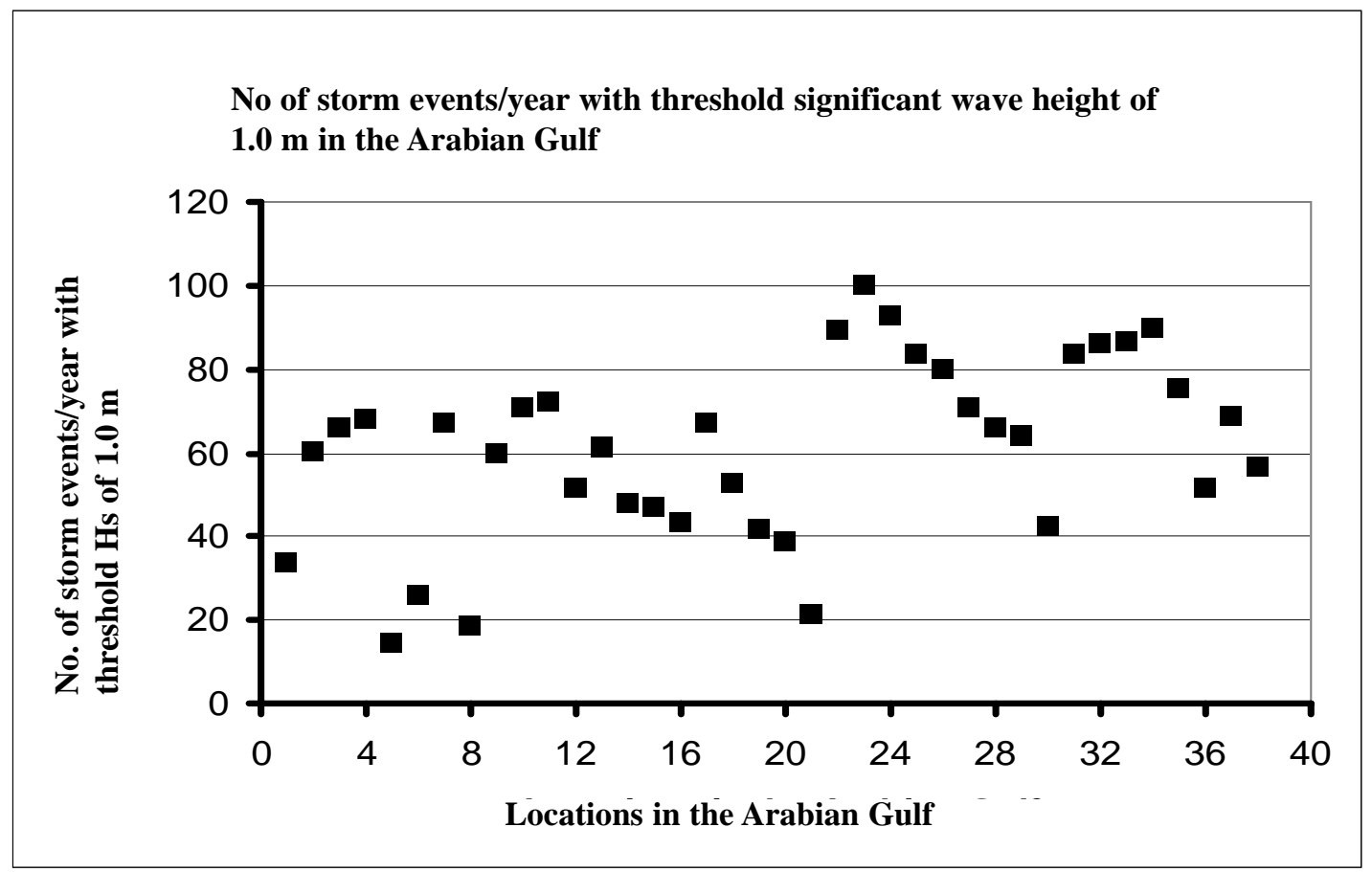

Figure 4. Number of storm events/year with threshold significant wave height of $1.0 \mathrm{~m}$ in the Arabian Gulf waters

of data, one can hence expect about 1095 to 2190 data points for each location, if the time interval between the data is considered as 4 days and 2 days respectively. It means that for each location, one can expect about 91 and 182 data points per year if the time interval between data is 4 days and 2 days respectively. For the present paper the number of storm events/year (Fig. 4) is 100 or less than 100, which means that the average time interval between the data for $1.0 \mathrm{~m}$ threshold value is 3 days or more. Hence the selection of $1.0 \mathrm{~m}$ threshold follows the recommendation of Mathiesen, et al. (1994).

It is seen that there are 9 locations which has more than 80 No. of storm events/year with threshold significant wave height of $1.0 \mathrm{~m}$. It is also seen that there are 14 loca- tions which have 60 to 80 storm events/year with threshold significant wave heights of $1.0 \mathrm{~m}$. There are six locations amongst the selected 38 locations with less than 40 storm events/year with threshold significant wave height of $1.0 \mathrm{~m}$. These important information are vital for marine operations around these locations. The data points used in the POT analysis are the peaks occurring during each storm with threshold wave height of $1.0 \mathrm{~m}$. The total number of data points used for the extreme wave analysis is hence 12 times the No. of storm events/year with threshold $H_{s}$ value of $1.0 \mathrm{~m}$ as provided in the above figure.

The data points for each location are arranged in descending order. The probability of exceedence, $Q$ is calculated using the formula. 
The Journal of Enginering Research Vol. 6, No. 1, (2009) 21-36

$Q=\left(i-C_{1}\right) /\left(N+c_{2}\right)$

Where

i : Rank

$N \quad$ : Total number of data points

$c_{1}=0.44$ and $c_{2}=0.12$ for Gumbel distribution and

$c_{1}=0.20+(0.27 / \alpha)$ and $c_{2}=0.20+(0.23 / \alpha)$ for Weibull

distribution, where $\alpha$ is the shape parameter. The value of $\alpha$ is varied from 0.8 to 1.3 with an increment of 0.05 and the value of $\alpha$, which gives best fit for the data set is selected.

The detailed description of Gumbel and Weibull distribution can be found from many sources (Kamphuis, et al. 2000). For the purpose of quick reference and use for the readers, the salient details of these distributions are provided in Annex. A.

\subsection{Prediction of the Wave Height for the Selected Return Period}

The return period, $T_{R}$ and the probability of exceedence are linked by the following expression

$Q=1 /\left(1 T_{R}\right)$

Where $l$ is the number of event/year. For the present problem, we know the total number of storm events exceeding threshold value of $H_{s}=1.0 \mathrm{~m}$ for each location in the Arabian Gulf waters. Since the data is for a total duration of 12 years, the value of 'l' can be calculated immediately (Refer Fig. 4).

Now according to Gumbel distribution, the wave height expected for a selected return period $H_{T R}$ can be estimated as follows (Kamphuis 2000):

$H_{T R}=g-b \operatorname{In}[\operatorname{In}(1 / P)]$

ie. $H_{T R}=g-b \operatorname{In}\left[\operatorname{In}\left\{\left(\mathrm{l}_{T R}\right) /\left(1 T_{R^{-1}}\right)^{1 / \alpha}\right\}\right]$

According to the Weibull distribution, the wave height expected for a selected return period $H_{T R}$ can be estimated from the following formula (Kamphuis 2000):

$H_{T R}=g+b[\operatorname{In}(1 / Q)]^{1 / \alpha}$

ie. $\left.H_{T R}=g+b\left[\operatorname{In}\left(\mathrm{l}_{T R}\right)\right]^{1 / \alpha}\right]$

Now it is possible to obtain the extreme wave height for any selected return period.

\subsection{Joint Probability of Mean Wave Periods and Significant Wave Heights}

Wave height and wave periods are independent parameters. However we can see that as wave height increases, it is likely that wave period also increase. On the other hand, the probability of occurrence of high waves and long periods are more pronounced than the probability of occurrence of high waves and short periods. Joint proba- bility of wave height and wave period is used for predicting the wave period for a wave height of any desired return periods Kamphuis 2000. An example of joint wave period-wave height distribution for location 23 in the Arabian Gulf waters is given in Table. 2.

The joint distribution is simplified by relating wave period to wave height via the combinations of greatest frequency. For example, in Table 2, interpolation gives $T_{\text {mean }}$ $=5.627 \mathrm{sec}$ corresponding to $H_{s}=2.625 \mathrm{~m}$. Now the significant wave height and mean wave period is related by the following equation:

$T_{\text {mean }}=C_{3}\left(H_{s}\right)^{C 4}$

The value of $C_{3}$ and $C_{4}$ and the corresponding coefficient of correlation $R^{2}$ is obtained for all the 38 locations in the Arabian Gulf waters and is given in Figs. 5, 6 and 7 respectively.

The figures show that the average coefficient of correlation is 0.948 , which is of acceptable value for using $C_{3}$ and $C_{4}$ values to obtain the mean wave period for a selected $H_{s}$ value. It is recommended to use the respective $C_{3}$ and $C_{4}$ values for the chosen locations for the estimation of Tmean. The average value of $C_{3}$ and $C_{4}$ is 4.398 and 0.2648 respectively and may be used for finding out the approximate value of the mean wave period for the Arabian Gulf waters for the selected significant wave heights corresponding to a desired return period of the event.

\section{Results and Discussions}

In the following are the steps used for the long-term prediction of waves in the Arabian Gulf:

a. The data set for each location is obtained based on peak over threshold value of significant wave height of 1.0 $\mathrm{m}$ for all 38 locations for the hindcasted data for the period from 1.1.1993 to 31.12.2004.

b. The wave heights obtained at each location are arranged in descending order.

c. The plotting formula, as discussed in Eq. 1 is used to reduce the wave height data to a set of points describing the probability of exceedence of wave height, $Q$.

$\mathrm{d}$. The wave height is then plotted against the reduced variate of Gumbel distribution (-In $[\operatorname{In}(1 / P)])$ and Weibull distribution $\left([\operatorname{In}(1 / Q)]^{1 / \alpha}\right)$.

e. A straight line is fitted by using least square techniques through the points to represent a trend. The slope and intercept is obtained. From this, the parameters of the probability distribution are obtained.

f. Eqs. 4 and 6 are used for predicting wave heights for chosen return period (12 year, 25 year, 50 year, 100 year, 200 year etc.) for Gumbel and Weibull distribution respectively.

A typical Gumbel distribution plot for location 23 is provided in Fig. 8. The equation of the best line fit and 
The Journal of Enginering Research Vol. 6, No. 1, (2009) 21-36

Table 2. Joint distribution of significant wave height and mean wave period for location 23 in the Arabian Gulf waters (Number of occurrences over 12 years)

Mean Wave Period, $\mathbf{T}_{\text {mean }}(\mathrm{Sec})$

\begin{tabular}{|c|c|c|c|c|c|c|c|c|c|c|c|}
\hline $\mathbf{H}_{\mathrm{s}}(\mathbf{m})$ & 0-1.0 & $\begin{array}{l}1.01- \\
2.0\end{array}$ & $\begin{array}{l}2.01- \\
3.0\end{array}$ & $\begin{array}{l}3.01- \\
4.0\end{array}$ & $\begin{array}{l}4.01- \\
5.0\end{array}$ & $\begin{array}{l}5.01- \\
6.0\end{array}$ & $\begin{array}{l}6.01- \\
7.0\end{array}$ & $\begin{array}{l}\text { 7.01- } \\
\mathbf{8 . 0}\end{array}$ & $\begin{array}{l}8.01- \\
9.0\end{array}$ & $\begin{array}{l}\text { Total } \\
\text { No. of } \\
\text { Occurr } \\
\text { ence }\end{array}$ & $\begin{array}{l}\text { Mean } \\
\text { value } \\
\text { (Sec) }\end{array}$ \\
\hline $0-0.25$ & 0 & 2519 & 21308 & 6202 & 350 & 35 & 0 & 0 & 0 & 30414 & 2.648 \\
\hline $0.251-0.5$ & 0 & 91 & 7930 & 21796 & 1308 & 102 & 0 & 0 & 0 & 31227 & 3.289 \\
\hline $0.51-0.75$ & 0 & 0 & 42 & 13349 & 2028 & 214 & 2 & 0 & 0 & 15635 & 3.654 \\
\hline $0.751-1.0$ & 0 & 0 & 0 & 3225 & 2360 & 144 & 1 & 0 & 0 & 5730 & 3.963 \\
\hline $1.01-1.25$ & 0 & 0 & 0 & 1391 & 3153 & 135 & 2 & 0 & 0 & 4681 & 4.233 \\
\hline $1.251-1.5$ & 0 & 0 & 0 & 276 & 6775 & 287 & 13 & 1 & 0 & 7352 & 4.505 \\
\hline $1.51-1.75$ & 0 & 0 & 0 & 6 & 4465 & 322 & 36 & 4 & 0 & 4833 & 4.583 \\
\hline $1.751-2.0$ & 0 & 0 & 0 & 0 & 1563 & 1145 & 26 & 4 & 0 & 2738 & 4.942 \\
\hline $2.01-2.25$ & 0 & 0 & 0 & 0 & 105 & 1288 & 31 & 2 & 0 & 1426 & 5.451 \\
\hline $2.251-2.5$ & 0 & 0 & 0 & 0 & 3 & 542 & 22 & 5 & 0 & 572 & 5.551 \\
\hline $2.51-2.75$ & 0 & 0 & 0 & 0 & 0 & 217 & 25 & 3 & 0 & 245 & 5.627 \\
\hline $2.751-3.0$ & 0 & 0 & 0 & 0 & 0 & 72 & 67 & 1 & 0 & 140 & 5.993 \\
\hline $3.01-3.25$ & 0 & 0 & 0 & 0 & 0 & 7 & 96 & 1 & 0 & 104 & 6.442 \\
\hline $3,251-3.5$ & 0 & 0 & 0 & 0 & 0 & 0 & 28 & 1 & 0 & 29 & 6.534 \\
\hline $3.51-3.75$ & 0 & 0 & 0 & 0 & 0 & 0 & 48 & 0 & 0 & 48 & 6.5 \\
\hline $3.751-4.0$ & 0 & 0 & 0 & 0 & 0 & 0 & 12 & 1 & 0 & 13 & 6.577 \\
\hline $4.01-4.25$ & 0 & 0 & 0 & 0 & 0 & 0 & 5 & 0 & 0 & 5 & 6.5 \\
\hline $4.251-4.5$ & 0 & 0 & 0 & 0 & 0 & 0 & 0 & 0 & 0 & 0 & - \\
\hline
\end{tabular}

The value of $C 3$ at different locations in the Arabian Gulf

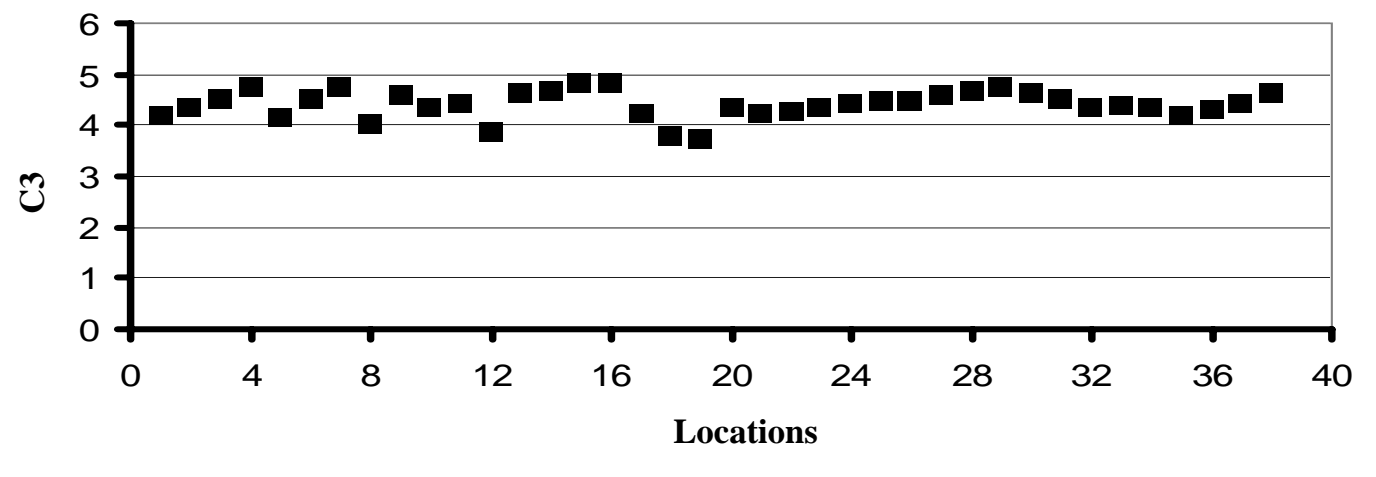

Figure 5. The value of $C_{3}$ for different locations in the Arabian Gulf waters

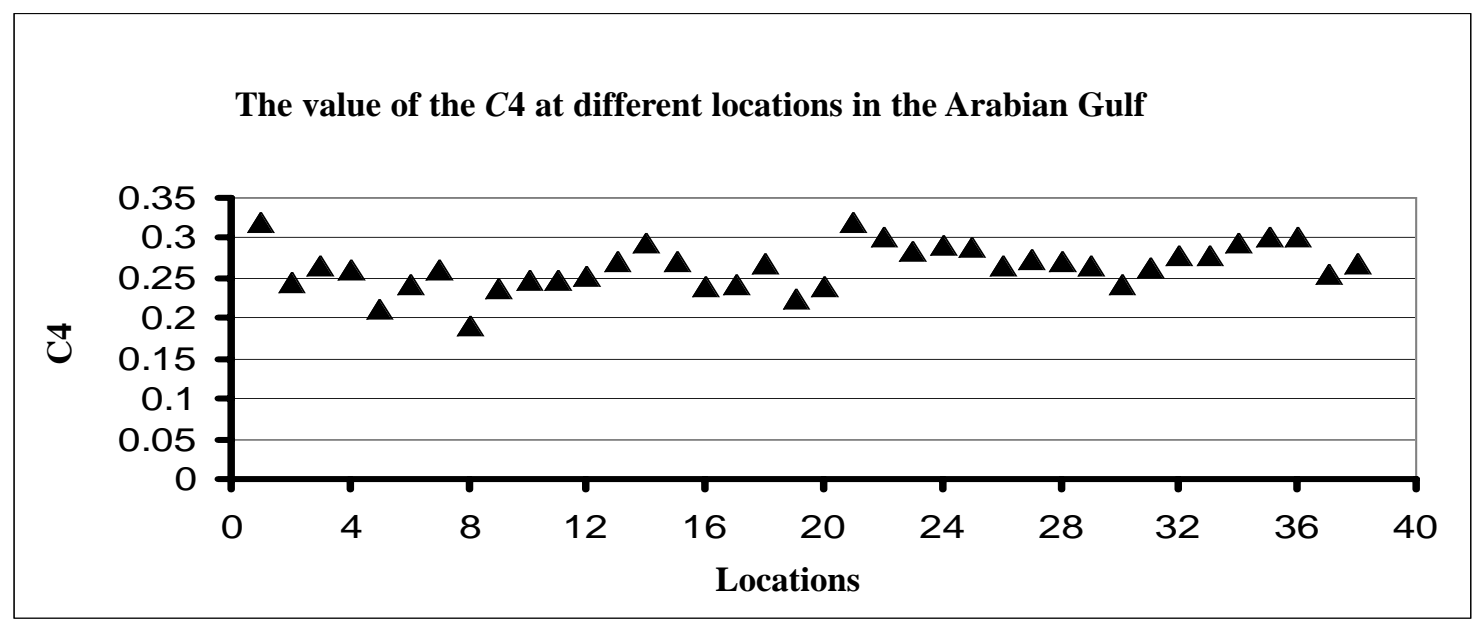

Figure 6. The value of $C_{4}$ for different locations in the Arabian Gulf waters 
The Journal of Enginering Research Vol. 6, No. 1, (2009) 21-36

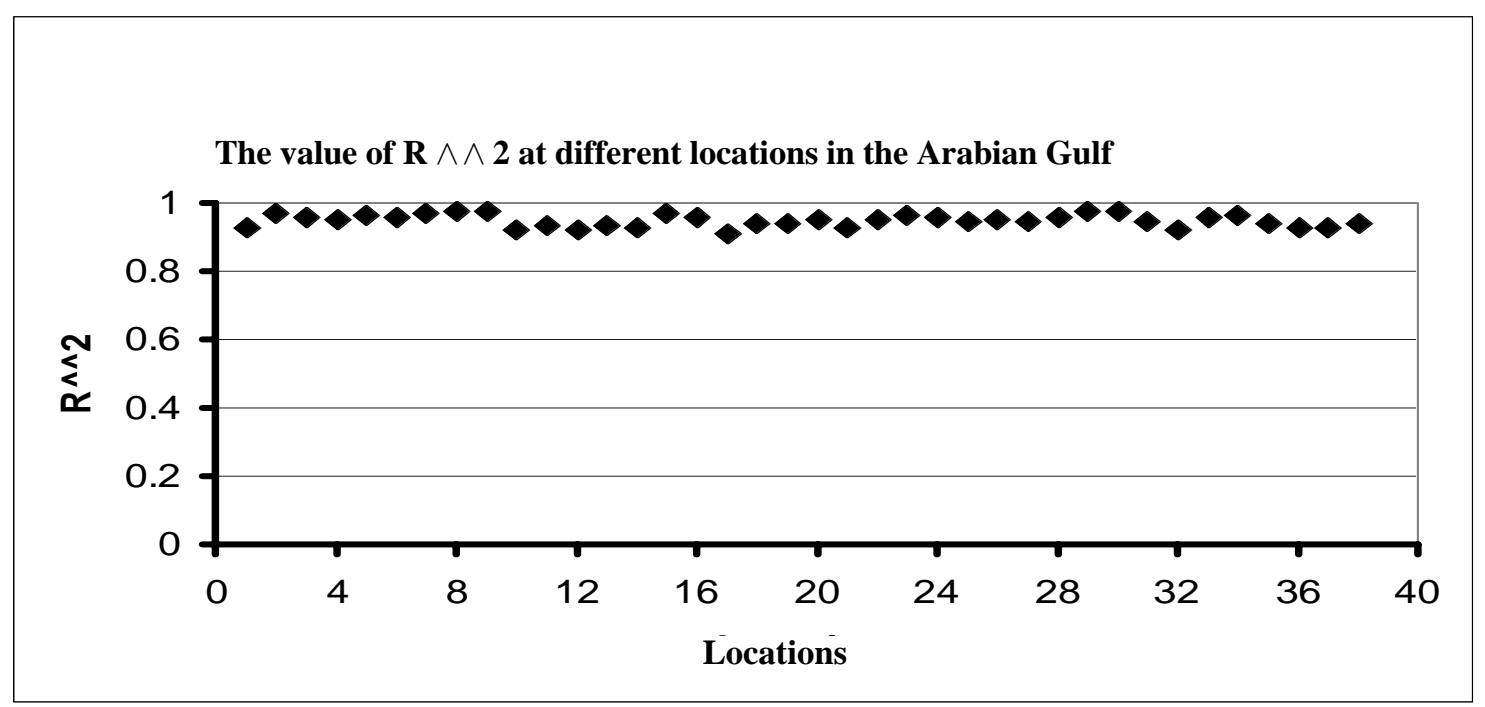

Figure 7. The value of $\mathbf{R}^{2}$ for different locations in the Arabian Gulf waters for Eqn. 7

the correlation coefficient are provided. For the same location, the Weibull distribution plot is given in Fig. 9 and the equation for the best line fit and the value of correlation coefficient is also given. Similar plots are prepared for all the 38 locations. It is found that Weibull distribution is better than Gumbel distribution for all the 38 locations.

The location parameter, scale parameter and the coefficient of regression obtained for all the 38 locations based on the Gumbel distribution are given in Figs. 10, 11 and 12 respectively. These parameters can be used in Eq. 4 in order to obtain the wave heights corresponding to the required return period. The location parameter varies from 1.18 to 1.59 and the scale parameter varies from 0.14 to 0.64. The coefficient of regression for most of the locations is closer to 0.95 (Except location 8 where the total number of data points with peak over threshold significant wave height of 1.0 is small compared to other locations) and hence one can have confidence in the best line fit for the data.

Similarly, the location parameter, scale parameter, shape parameter and the coefficient of regression obtained for all the 38 locations based on the Weibull distribution are given in Figs. 10, 14,15 and 16. These parameters can be used in Eqn. 6 to get wave heights corresponding to any required return period. It is seen that the Location parameter varies from 0.904 to 1.044 , scale parameter from 0.24 to 1.126. The shape parameter for the best line fit is also varies from 0.95 to 1.3. The coefficient of regression for the best line fit for most of the locations fit is closer to 1.0 and is better than the corresponding Gumbel distribution fits for different locations. Hence it is recommended to use Weibull distribution for extreme wave height prediction in the Arabian Gulf waters.

The predicted wave heights for the different locations based on Gumbel distribution for return periods of 12 years, 25 years, 50 years, 100 years and 200 years are provided in Fig. 17 for quick reference. Similar plot based on the Weibull distribution is provided in Fig. 18.

Also a plot showing the predicted extreme significant wave height for 100 year return period in the Arabian Gulf at different locations is given in Fig. 19 for quick reference.

In general the extreme waves on the territorial waters of Kuwait, Saudi Arabia, Bahrain, Qatar and UAE are smaller compared to the Iran's territorial waters and in the Arabian Gulf midway between the longitudinal boundaries of both the sides. If we consider the whole Arabian Gulf, then the predicted 100 year significant wave varies from $2.2 \mathrm{~m}$ (in the Saudi Arabian territorial waters) to $7.0 \mathrm{~m}$ (midway between UAE and Iran). Even on the longitudinal direction of the Arabian Gulf along its midway, the 100 year return period ways are of the order of $5 \mathrm{~m}$ in the Northern part of the Gulf and is about 6.0 to $7.0 \mathrm{~m}$ in the southern part of the Gulf. This could be due to the higher water depths and longer fetch length available for the southern part of the gulf for the North West winds. Design of any marine structures in these locations need to consider this points for safe and economic designs. The territorial waters off UAE coast, where large number of artificial coastal development projects are going on, the 100 year return period significant waves are of the order of 5.0 to $5.5 \mathrm{~m}$. The complete picture of the predicted extreme waves for different return periods in the Arabian Gulf can be used for economic and safe design of the projects proposed for the near future and also for assessing the reserve strengths of different ocean structures functioning at present in these waters.

Collection of more number of reliable past data is very important for prediction of the extreme values with different return periods. Simiu, et al. (1978) found that the sampling error in estimating a wind speed with a 50 year return period from 25 years of data, with a $68 \%$ confident level is about $\pm 7 \%$. The error in estimating the 1000 year return period value from 25 years of data is calculated to be $\pm 9 \%$. On similar tone, the error in estimating the 200 year and 100 year return period value from 12 years of data would be $\pm 6 \%$ and $\pm 4 \%$. The users should consider this uncertainty while using the predicted extreme wave height data for the design purpose. 


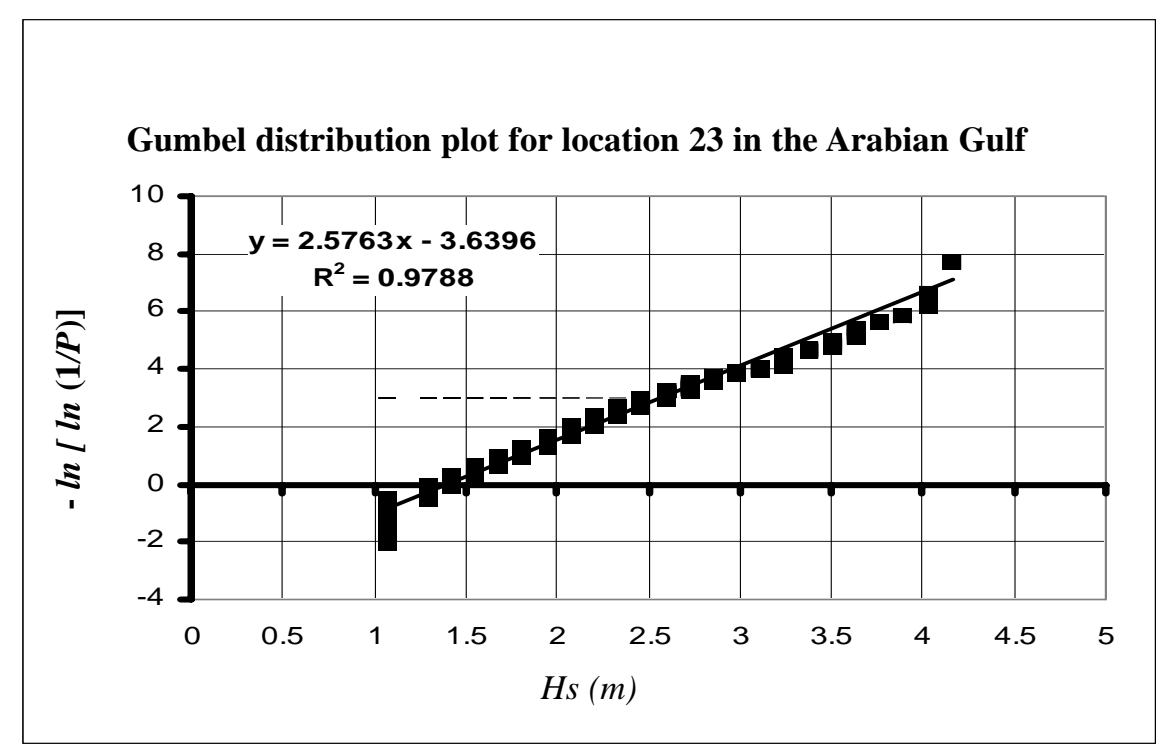

Figure 8. Gumbel distribution plot for location 23 in the Arabian Gulf

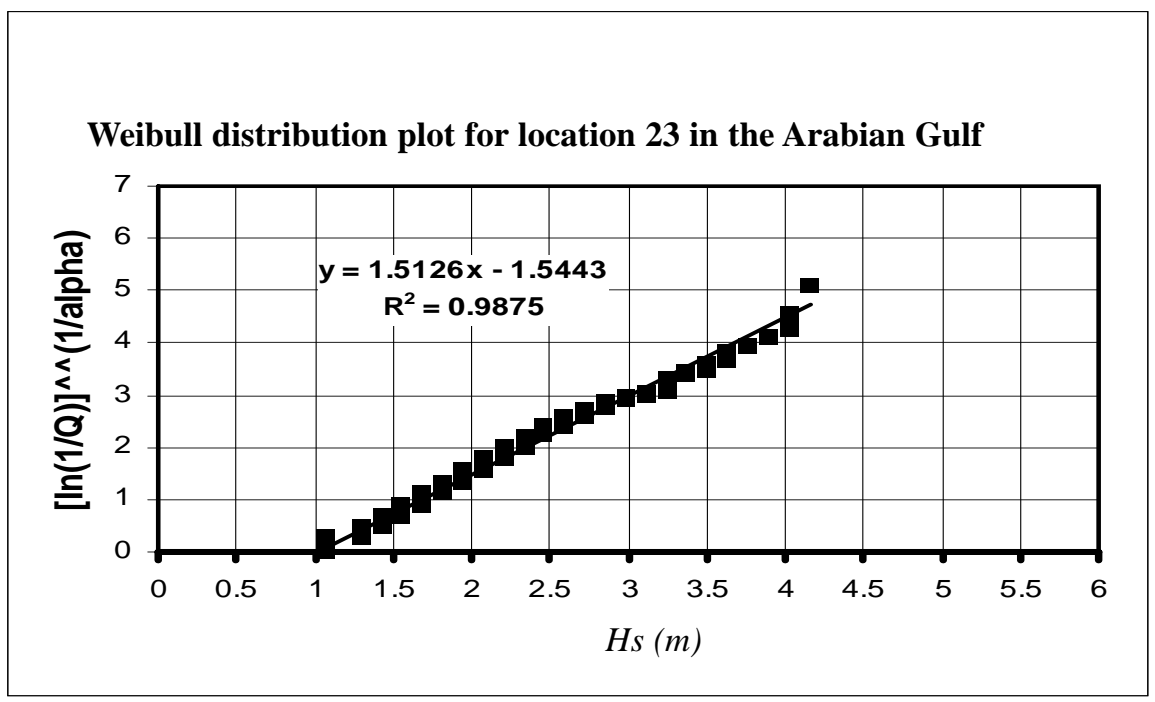

Figure 9. Weibull distribution plot for location 23 in the Arabian Gulf

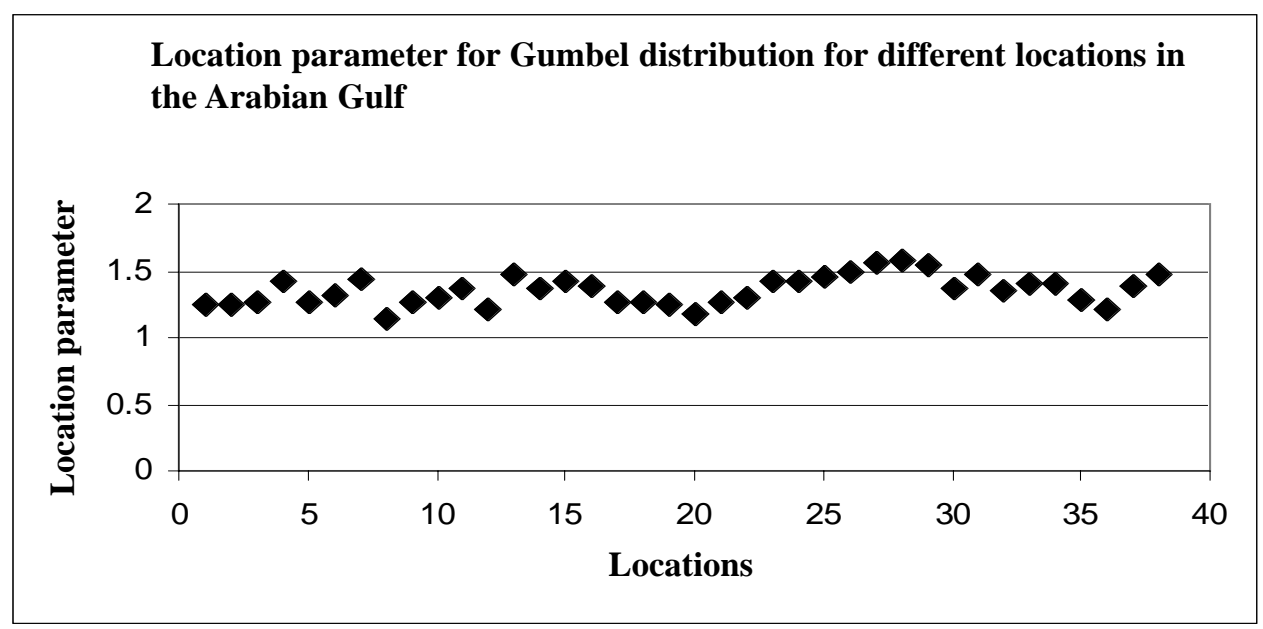

Figure 10. Location parameter based on Gumbel distribution for 38 locations in the Arabian Gulf 


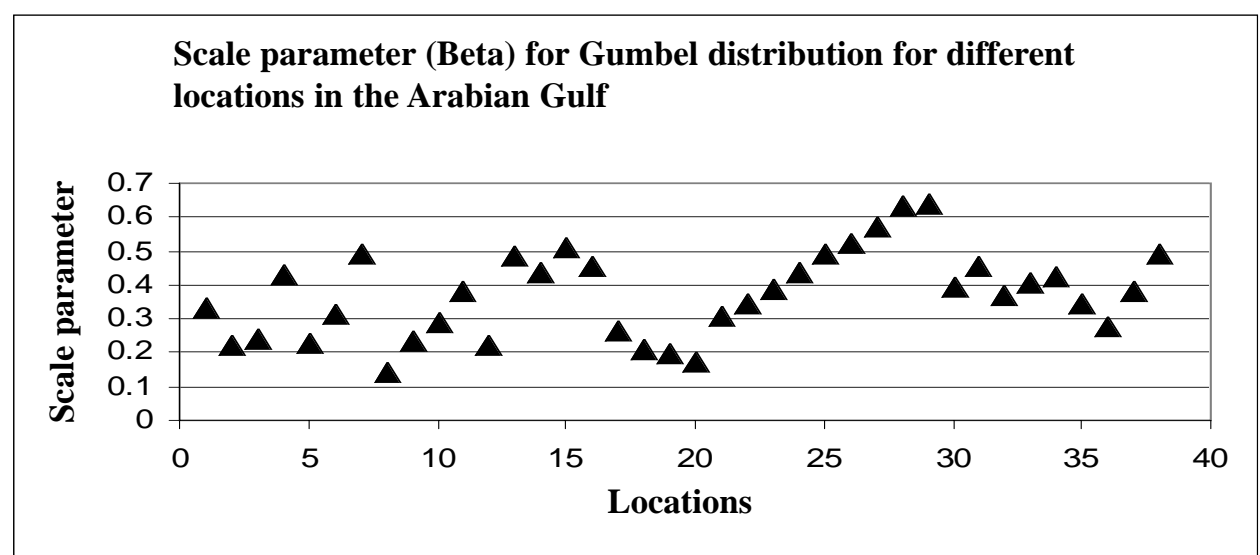

Figure 11. Scale parameter based on Gumbel distribution for 38 locations in the Arabian Gulf

Coefficient of Regression for the best line fit of Gumbel distribution for different locations in the Arabian Gulf

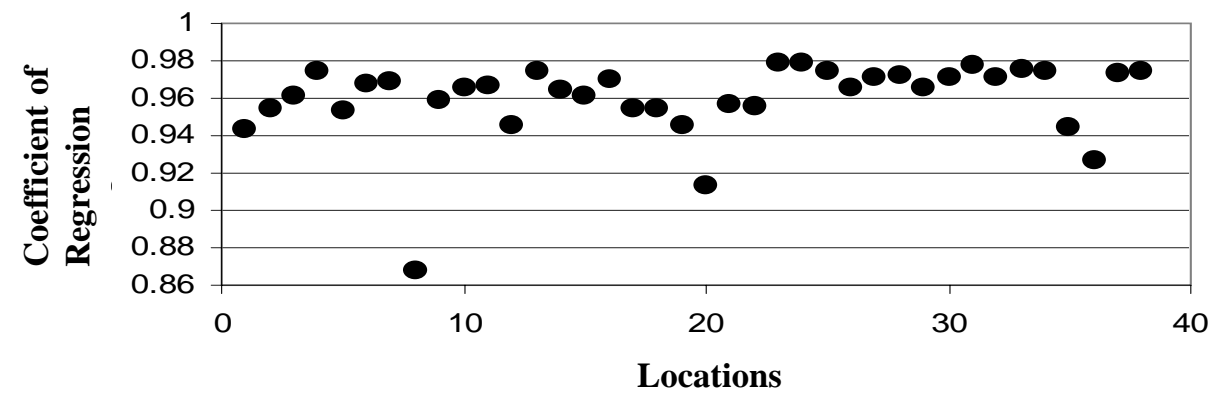

Figure 12. Coefficient of regression for the best line fit for Gumbel distribution for 38 locations in the Arabian Gulf

Location parameter (Gamma) for Weibull distribution for different locations in the Arabian Gulf

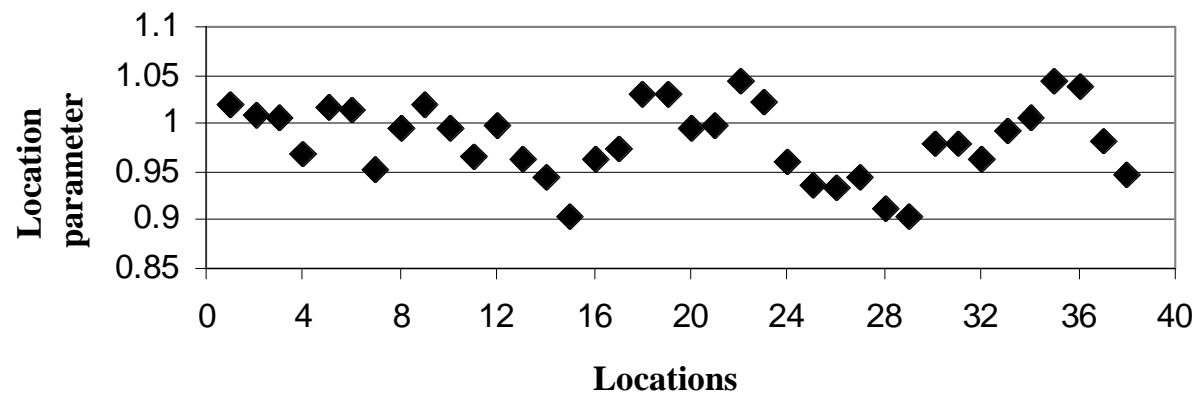

Figure 13. Location parameter based on weibull distribution for $\mathbf{3 8}$ locations in the Arabian Gulf 
Scale parameter (Beta) for Weibull distribution for different locations in the Arabian Gulf

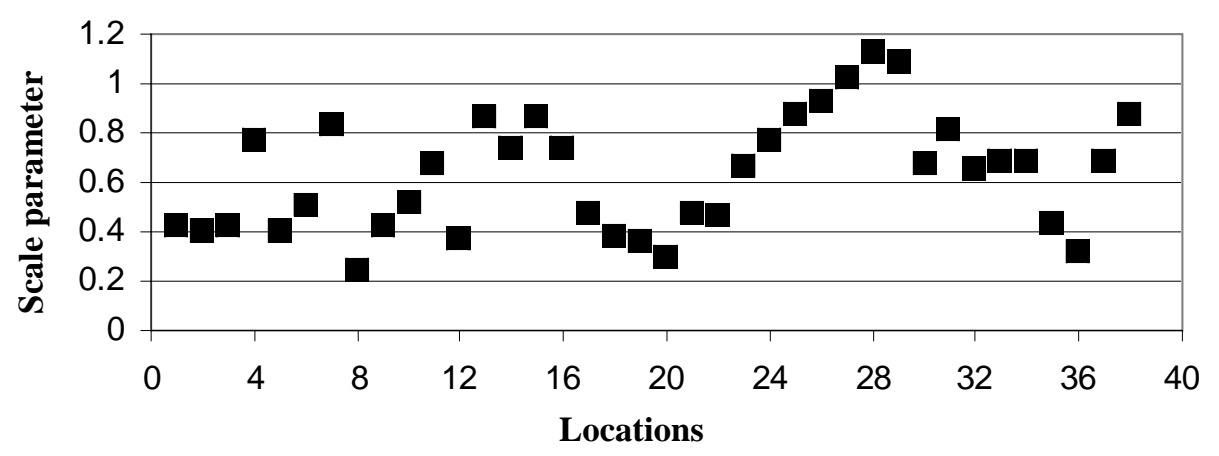

Figure 14. Scale parameter based on Weibull distribution for 38 locations in the Arabian Gulf

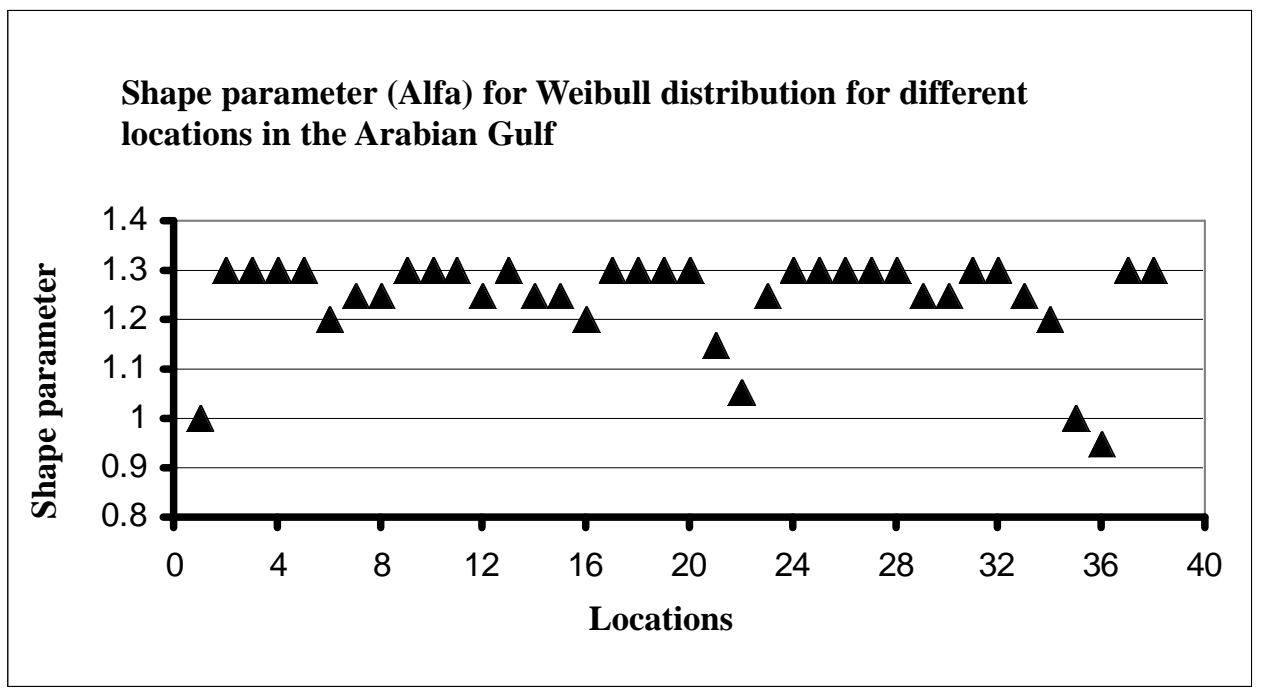

Figure 15. Shape parameter based on Weibull distribution for 38 locations in the Arabian Gulf

Coefficient of Regression for the best line fit of Weibull distribution for different locations in the Arabian Gulf

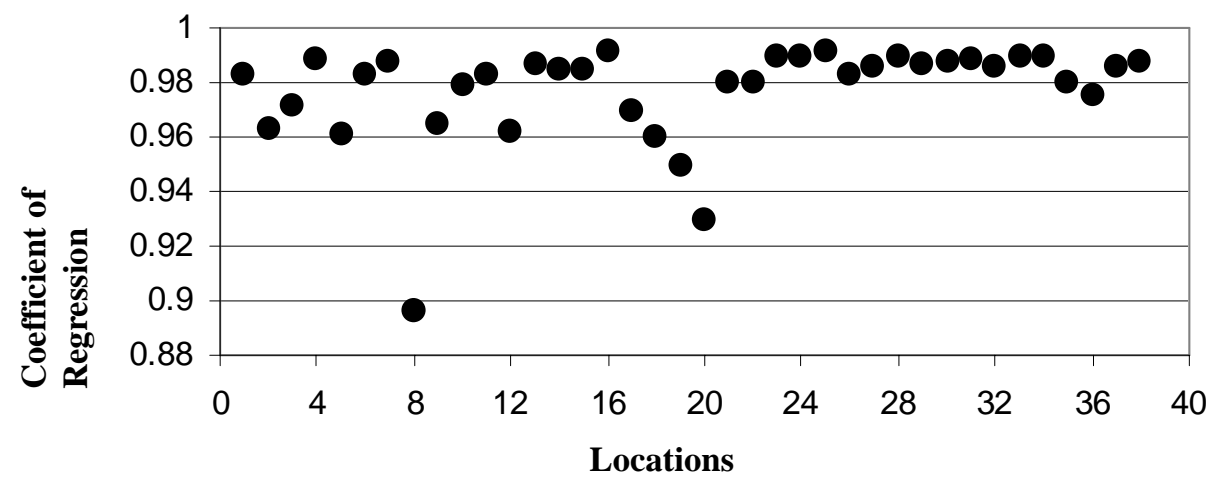

Figure 16. Coefficient of Regression for the best line fit for Weibull distribution for 38 locations in the Arabian Gulf 


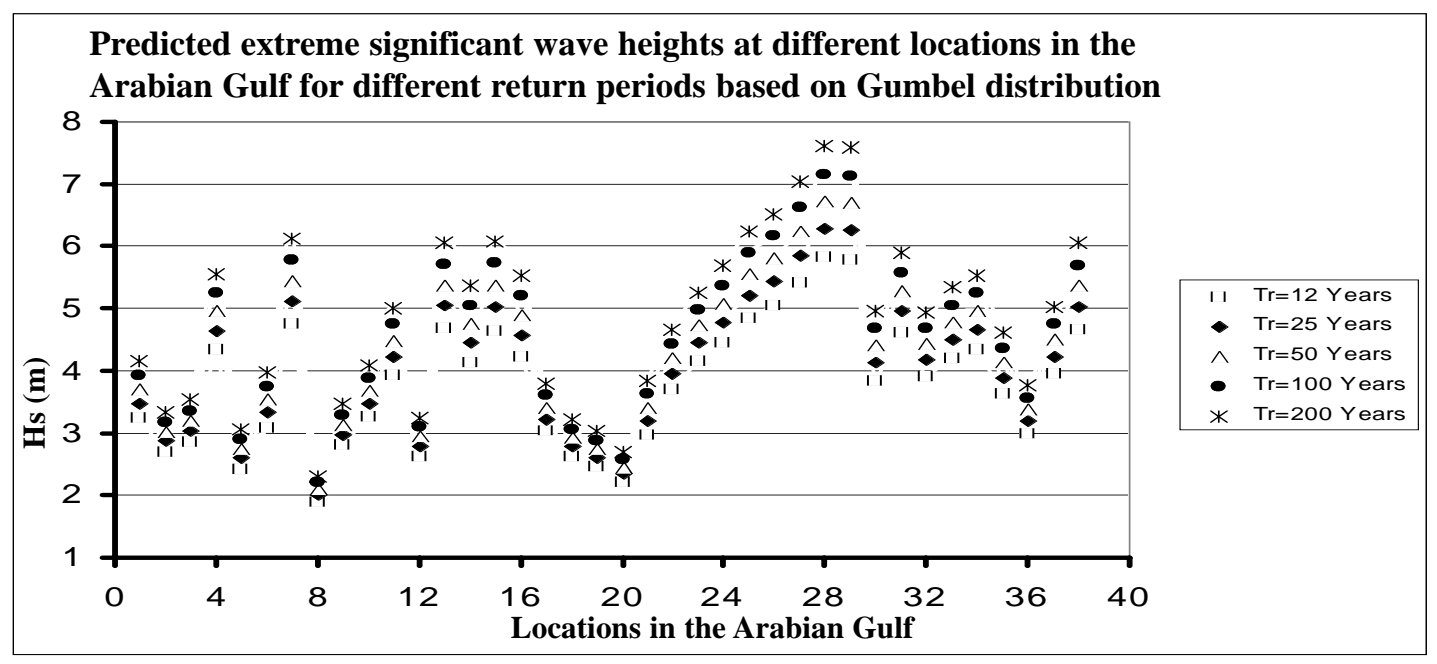

Figure 17. Predicted extreme significant wave heights in the Arabian Gulf waters for different return periods based on Gumbel distribution

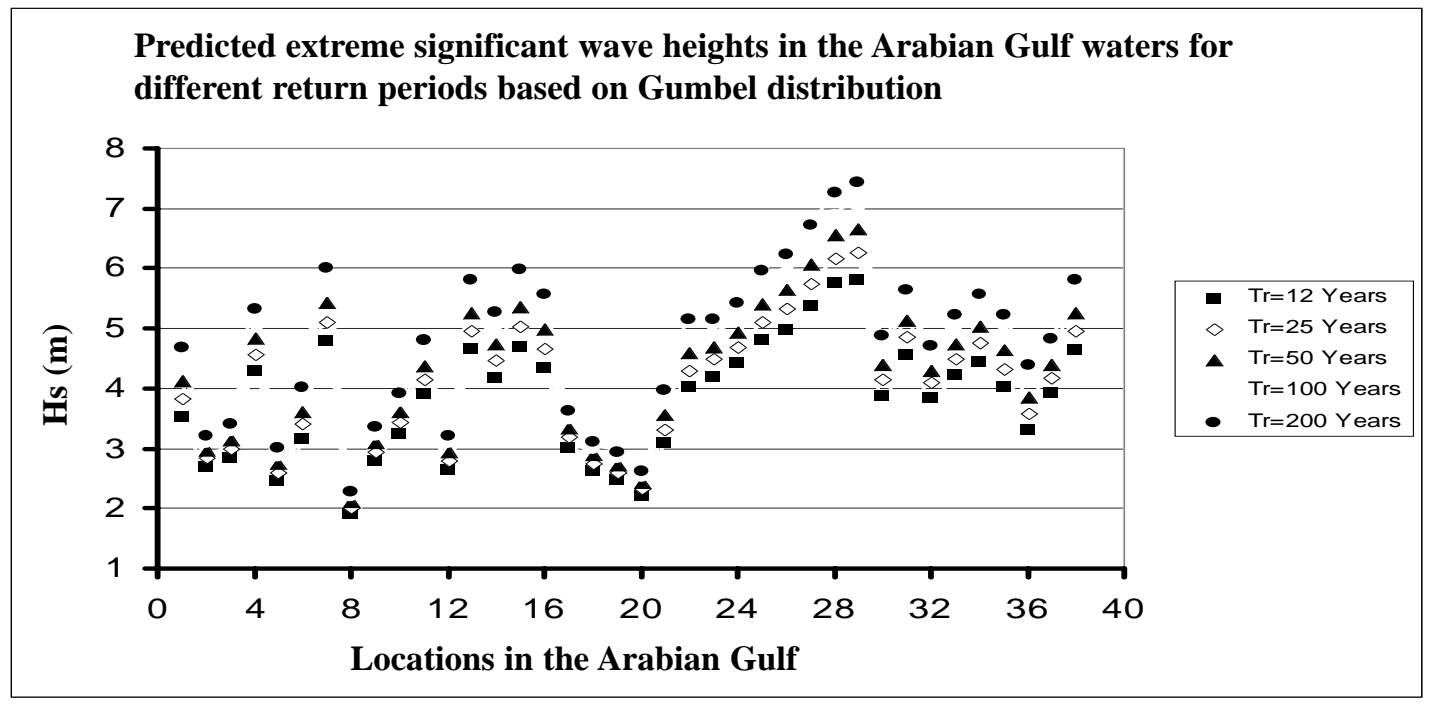

Figure 18. Predicted extreme significant wave heights in the Arabian Gulf waters for different return periods based on Weibull distribution

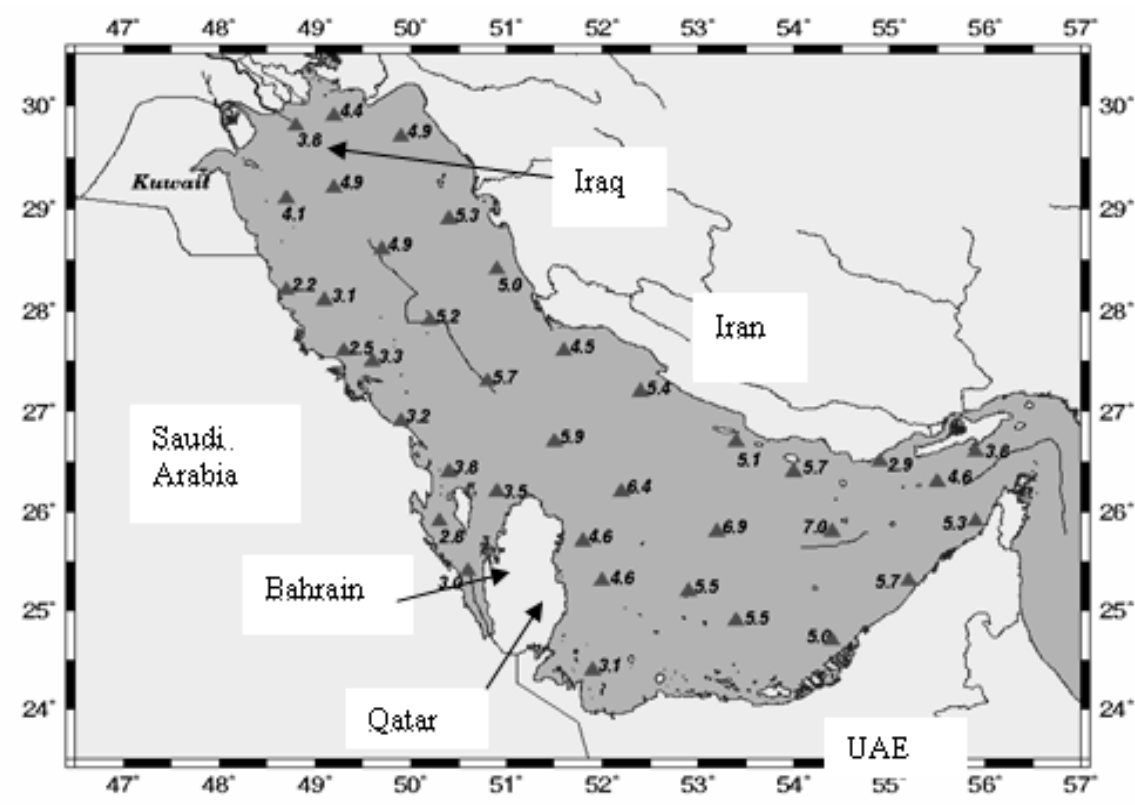

GMT May 23 10:43:50 2006

Figure 19. Predicted extreme significant wave heights for 100 year return periods in the Arabian Gulf waters 


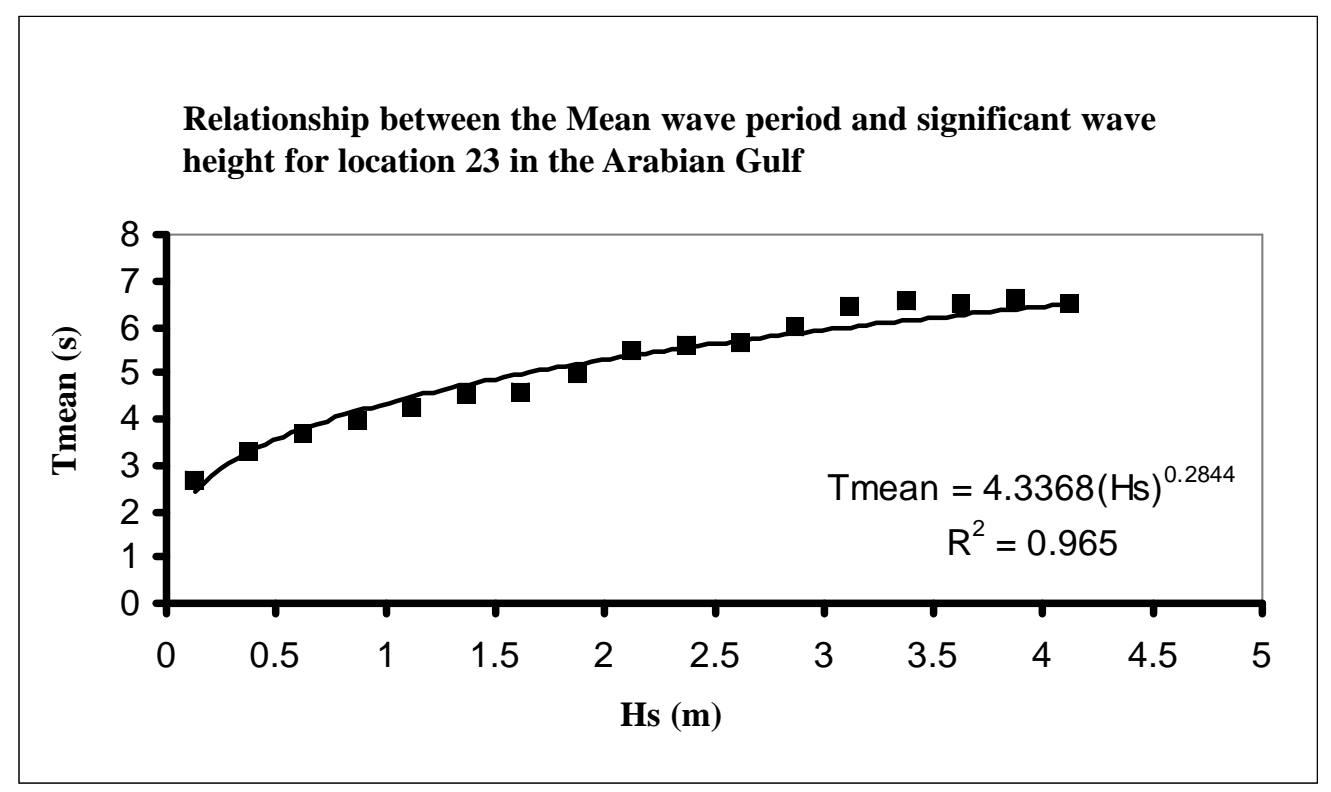

Figure 20. Relationship between the mean wave period and significant wave height for location 23 in the Arabian Gulf

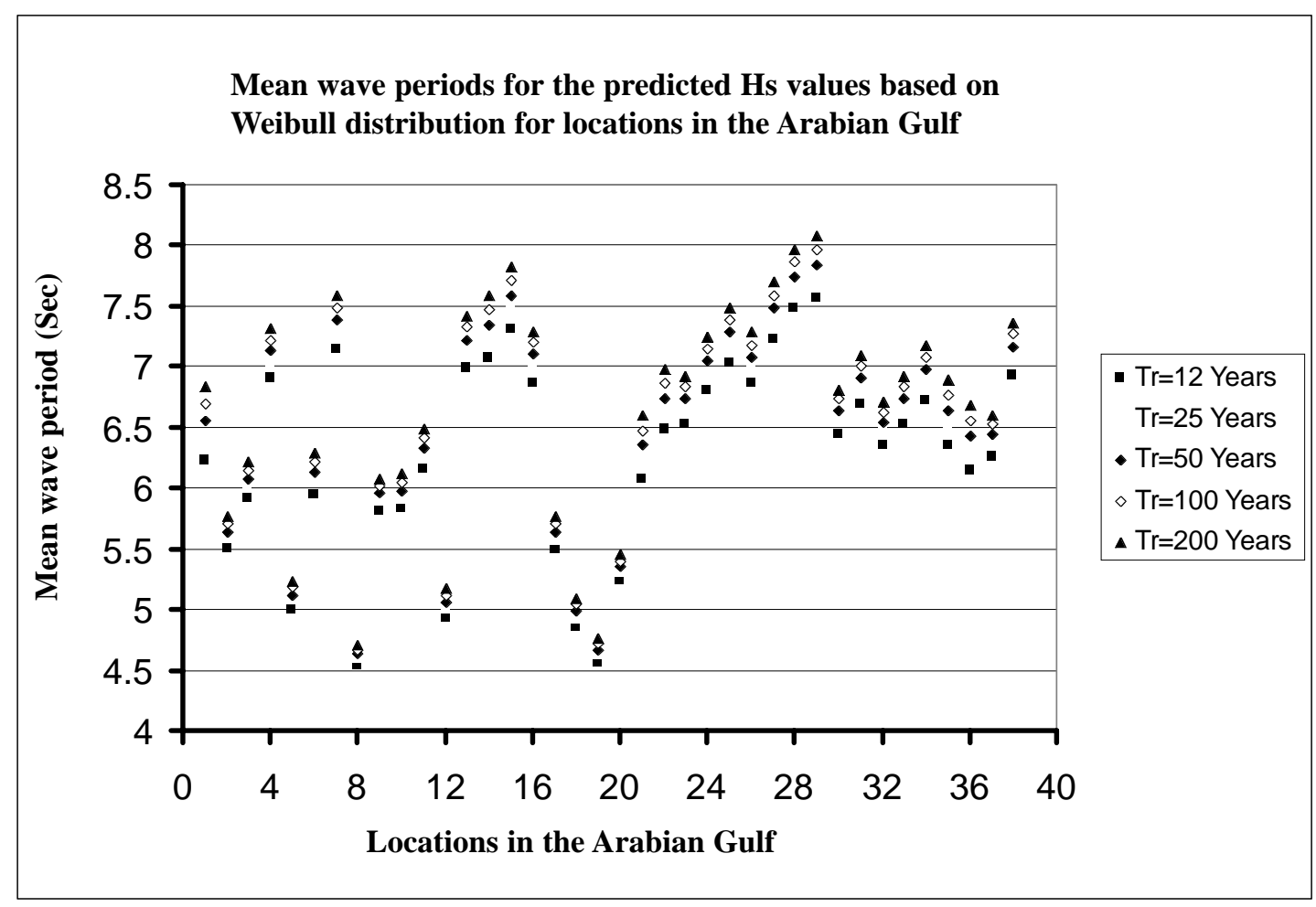

Figure 21. The predicted mean wave period for significant wave height obtained based on Weibull for 12, 25, 50, 100 and 200 year return periods

A typical plot showing the relationship between the significant wave height and mean wave period for location 23 is provided in Fig. 20. The best fit polynomial equation and the coefficient of regression is given in the plot.

For all the 38 locations in the Arabian Gulf, similar exercise is carried out to obtain the mean wave periods for different return periods, viz. 12, 25, 50, 100 and 200 years and the mean wave period obtained is provided in Fig. 21.
It can be seen that the mean wave period range from $4.5 \mathrm{~s}$ to $8.1 \mathrm{sec}$ when all the locations and all the return period range of 12 to 200 years are considered together. In fact, one can see that for a selected location, the difference between the mean wave period for 12 year return period and 200 year return period is only of the order of $0.5 \mathrm{sec}$, where as the location has very significant effect on change of Mean wave period. For example, for location 8 (Saudi 


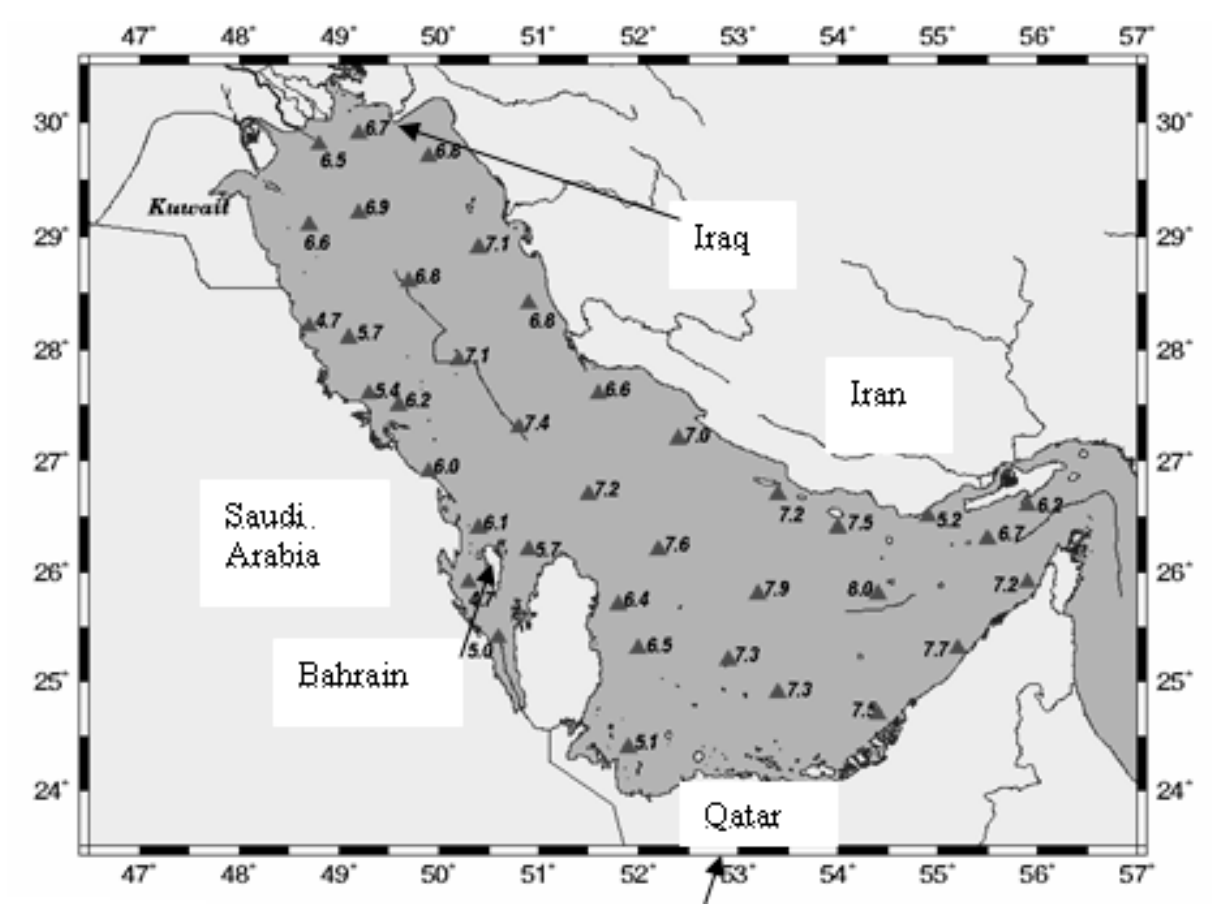

Figure 22. Mean wave period in the Arabian Gulf for 100 year return periods

Arabian territorial waters), the mean wave period is in between 4.5 and $5 \mathrm{sec}$ for return periods in the range of 12 to 200 years, whereas for location 28 (Offshore in between UAE and Iran), the mean wave period is in between 7.5 and $8 \mathrm{sec}$ for return periods in the range of 12 to 200 years. This aspect is very important in the design of ocean structures which are very sensitive for wave periods (Like the wave transmission characteristics of floating breakwater, which is very sensitive for wave period).

For clarity and quick reference, Fig. 22 is provided, which shows the mean wave period at different locations in the Arabian Gulf for 100 year return period event.

\section{Conclusions}

Gumbel and Weibull extreme value distributions are used in order to obtain significant wave heights at 38 different marine locations in the Arabian Gulf waters. Data obtained based on the WAM model for 12 years are used. Peak over threshold of $1.0 \mathrm{~m}$ is used for synthesizing the raw data. Based on Joint probability analysis, the mean wave period for the significant wave heights of intended return periods were obtained based on polynomial fit between the mean period and significant wave period. In the following are the conclusions obtained out of this investigation.

1. The Weibull distribution is very suitable for extreme wave height prediction in the Arabian Gulf waters.

2. Though the Arabian Gulf covers an area of about 226,000 square $\mathrm{km}$, the extreme significant wave height vary from $2.2 \mathrm{~m}$ to $7.0 \mathrm{~m}$ for 100 year return period, among these 38 locations. This spatial variation of the wave height must be considered for design of marine structure in these locations.
3. In general the value of extreme significant wave heights are smaller in the territorial waters of Kuwait, Saudi Arabia, Bahrain, Qatar compared to the territorial waters of UAE and Iran.

4. The maximum value of the 100 year return period significant wave height is $7.0 \mathrm{~m}$ and it is expected to occur in deeper waters in between UAE and Iran (Around location 28).

5. It is found that the mean wave period in the Arabian Gulf waters is ranging from 4.5 sec to 8.1 sec for the significant wave heights corresponding to 100 year return period.

6. The mean wave periods are more sensitive for special variations rather than return periods.

7. Variation of return period from 12 years to 200 years has increased the mean wave period by 0.5 sec only, whereas variation of space from coastal waters of Saudi Arabia to the offshore waters of UAE has changed the 100 year return period mean wave period from $4.7 \mathrm{sec}$ to $8.0 \mathrm{sec}$.

A large number of coastal and offshore projects are in progress and many new projects are planned for the near future in the Arabian Gulf waters. The results of the present study will be highly useful for optimal design of different types of sea structures in the Arabian Gulf.

\section{Acknowledgments}

The authors wish to express their gratitude to Kuwait Foundation for Advancement of Science for partially sponsoring the project, and thanks to Kuwait Institute for Scientific Research, Kuwait for providing all the infrastructure facilities to carry out this work. 


\section{References}

Al-Salem, K., Rakha, K., Sulisz, W. and Al-Nassar, W., 2005, "Verification of a WAM Model for the Arabian Gulf", Arabian Coast Conf., Dubai. UAE.

Al-Yamani, F.Y., Bishop, J., Ramadhan, E., Al-Husaini, M. and A. Al-Ghadban, 2004, " Oceanographic Atlas of Kuwait's Waters," Kuwait Institute for Scientific Research, Kuwait. p. 203.

Caires, S. and Sterl, A., 2005, "100-Year Return Value Estimates for Ocean Wind Speed and Significant Wave Height from the ERA-40 Data", J. of Climate, Vol. 18, pp. 1032-1048.

Cardone, V.J., Pierson, W.J. and Ward, E.G., 1976, "Hindcasting the Directional Spectra of Hurricane Generated Waves", J. of Petrol. Tech., Vol. 28, pp. 385-394.

Coles, S., 2001, “An Introduction to Statistical Modeling of Extreme Values", Springer-Verlag, p. 208.

Denis, M. St., 1969, "On Wind Generated Waves", In topics in Ocean Engineering, ed. C.L. Bretschneider, Gulf Publishing Co., Texas, Vol. I, pp. 37-41.

Denis, M. St., 1973, "Some Cautions on the Employment of the Spectral Technique to Describe Waves of the Sea and the Response Thereto of Oceanic Systems", Proc. Offshore Technology Conference, Houston, Paper No. OTC 1819, pp. 827-837.

El-Gindy, A. and Hegazi, M., 1996, "Atlas on Hydrographic Conditions in the Arabian Gulf and the Upper Layer of the Gulf of Oman”, University of Qatar, p. 170.

Elshorbagy, W., Azam, M.H. and Taguchi, K., 2006, "Hydrodynamic Characterization and Modeling of the Arabian Gulf", J. of Waterway, Port, Coastal and Ocean Engineering, ASCE, Vol. 132(1), pp. 47-56.

Emery, K.O., 1956, "Sediments and Water of the Persian Gulf", Bull. Amer. Ass. Petrol. Geol., Vol. 40(10), pp. 2354-2383.

Ferreira, J.A. and Guedes Soares, C., 1998, "An Application of the Peaks Over Threshold Method to Predict Extremes of Significant Wave Height", J. Offshore Mech. Arct. Eng., Vol.120, pp. 165-176.

Goda, Y., Hawkes, P., Mansard, E., Martin, M.J., Mathiesen, E., Peltier, E., Thompson, E. and Van Vledder, G., 1993, "Intercomparison of Extremal Wave Analysis Methods Using Numerically Simulated Data", Proc. 2nd Int. Symp. On Ocean Wave Measurement and Analysis, ASCE, New Orleans, pp. 963-977.

Goda, Y., 1992, "Uncertainty of Design Parameters from Viewpoint of Extreme Statistics", J. of Offshore Mechanics and Arctic Engineering., ASME, Vol. 114, pp. 76-82.
Gringorten, I.I., 1963, "A Plotting Rule for Extreme Probability Paper", J. of Geophys. Res., Vol. 68, pp. 813-814.

Gumbel, E.J., 1958, "Statistics of Extremes”, Columbia University Press, New York.

Jahns, H.O. and Wheeler, J.D., 1973, "Long-Term Wave Probabilities Based on Hindcasting of Severe Storms", J. of Petrol. Tech., Vol.25, pp. 473-486.

Kamphuis, J.W., 2000, "Introduction to Coastal Engineering and Management," Advanced Series on Ocean Engineering, Vol. 16, World Scientific, Singapore, Chapter. 4. Long term Wave Analysis. pp. 81-102.

Kimball, B.F., 1960, "On the Choice of Plotting Positions on Probability Paper", J. of Amer. Stat. Assn., Vol. 55, pp. 546-560.

Leadbetter, M.R., 1991, "On a Basis for "Peak Over Threshold" Modeling", Stat. Prob. Lett., Vol. 12, pp. 357-362.

Mathiesen, M., Hawkes, P., Martin, M.J., Thompson, E., Goda, Y., Mansard, E., Peltier, E. and Van Vledder, G., 1994, "Recommended Practice for Extreme Wave Analysis", J. Hydraulic Research., IAHR, Vol. 32, pp. 803-814.

Neelamani, S., Al-Salem, K. and Rakha, K., 2006, "Extreme Waves for Kuwaiti Territorial Waters", Communicated to Ocean Engineering, Pergaman Press, UK.

Nolte, K.G., 1973, "Statistical Methods for Determining Extreme Sea States", Proc. 2nd International Conference on Port and Ocean Engineering Under Arctic Conditions, Univ. of Iceland, pp. 705-742.

Petrauskas, C. and Aagaard, P., 1971, "Extrapolation of Historical Storm Data for Estimating Design Wave Height", J. of Soc. Petrol. Eng., Vol. 11, pp. 23-37.

Purser, B.H. and Seibold, E., 1973, "The Principal Environmental Factors Influencing Holocene Sedimentation and Diagenesis in the Persian Gulf", In: "Persian Gulf", Purser, B.H. (ed), Berlin, pp. 1-9.

Rakha, K.A., Al-Salem, K. and Neelamani, S., 2007, "Hydrodynamic Atlas for Kuwaiti Territorial Waters", Kuwait Journal of Science and Engineering. Vol. 34 (1A), pp. 143-156

Sarpkaya, T., de St. M. and Isaacson, Q., 1981, "Mechanics of Wave Forces on Offshore Structures", Van Nostrand Reinhold Company, New York, USA.

Simiu, E., Bietry, J. and Filliben, J.J., 1978, "Sampling Errors in Estimation of Extreme Winds," J. of the Structural Division, ASCE 104, pp. 491-501. 


\section{Appendix}

\section{Gumbel Distribution}

The Gumbel distribution is given as

$\mathrm{P}=\exp [-\exp \{-(\mathrm{H}-\mathrm{g}) / \mathrm{b}\}]$

Where

$\mathrm{P}=$ Probability of non exceedence $(\mathrm{P}=1-\mathrm{Q})$

$\mathrm{g}=$ Location parameter and

$\mathrm{b}=$ Scale parameter.

Eqn. 1 is linearised by taking logs on both sides twice and it becomes

$-\operatorname{In}[\operatorname{In}(1 / \mathrm{P})]=(1 / \mathrm{b}) \mathrm{H}-(\mathrm{g} / \mathrm{b})$

$-\operatorname{In}[\operatorname{In}(1 / \mathrm{P})]$ is called as the reduced variate of Gumbel distribution.

For the data set described, a least square best line fit is made and the value of $\quad b$ and $g$ is obtained from the slope and intercept of the best line fit.

\section{Weibull Distribution}

The Weibull distribution is a three parameter di stribution and is given as

$\mathrm{P}=1-\exp \left[-\{(\mathrm{H}-\mathrm{g}) / \mathrm{b}\}^{\mathrm{a}}\right]$

Which may also be expressed as

$\mathrm{Q}=\exp \left[-\{(\mathrm{H}-\mathrm{g}) / \mathrm{b}\}^{\mathrm{a}}\right]$

where á is the shape parameter, which can be varied from 0.8 to 1.3 .

For the purpose of linear transformation, take logarithm on both sides and after reorganization, we get

$[\operatorname{In}(1 / \mathrm{Q})]^{1 / a ́}=(1 / \mathrm{b}) \mathrm{H}-(\mathrm{g} / \mathrm{b})$

$[\operatorname{In}(1 / \mathrm{Q})]^{1 / a}$ is called as the reduced variate of Weibull distribution.

Again, for the data set described, a least square best line fit is made and the value of $\quad b$ and $g$ is obtained from the slope and intercept of $t$ he best line fit. As discussed, the shape parameter á is varied from 0.8 to 1.3 in step of 0.05 and the best line fit is selected based on the highest value of correlation coefficient. 